Running head: CONTINUING PROFESSIONAL DEVELOPMENT

Continuing Professional Development in School Psychology:

Perspective from Hong Kong

Shui-fong Lam and Mantak Yuen

The University of Hong Kong, China

Shui-fong Lam, Psychology Department, the University of Hong Kong;

Mantak Yuen, Faculty of Education, the University of Hong Kong.

The data reported in this paper were collected in conjunction with the ISPA International School Psychology Survey. We added items to this survey when it was conducted in Hong Kong. The results reported in this paper were based primarily on the findings of these additional items. The authors wish to thank Dr. Shane Jimerson and the Research Committee of International School Psychology Association for developing the ISPS and their permission to add these items to the survey. We owe a lot to Dr. Shane Jimerson and Mr. Peter Shea for their critical comments and constructive suggestions to the manuscript. We are also grateful to Ms. Virginia Cheung and Ms. Sherin Ke for their assistance in the project, and the school psychologists who took the time to complete the survey.

Correspondence concerning this article should be addressed to Shui-fong Lam, Psychology Department, The University of Hong Kong, Pokfulam Road, Hong Kong. E-mail: lamsf@hkusub.hku.hk

Keywords: School Psychology, Supervision, Continuing Professional Development, Hong Kong 
CONTINUING PROFESSIONAL DEVELOPMENT 2

\title{
Continuing Professional Development in School Psychology:
}

Perspective from Hong Kong

\begin{abstract}
A questionnaire survey was conducted in Hong Kong to investigate the types, frequency, popularity, and quality of continuing professional development (CPD) in school psychology. The results indicated that $60 \%$ of the 32 respondents received regular supervision, however, the majority met their supervisors less than once a month. The characteristics of their supervisors also suggested that the supervision tended to be administrative instead of professional in nature. The most popular CPD activities were attending conferences/seminars, self-study and individual supervision. Large variation was found among the school psychologists from different work settings. The few school psychologists in private practice reported the least amount of CPD activities. The results are discussed with reference to the need to establish regulatory systems with mandatory CPD.
\end{abstract}


Amidst the mounting pressure for providing quality services in an era of rapid changes,

it is difficult to argue against the need for school psychologists to continue their professional development. At the turn of millennium, there is an emerging international consensus in the profession that continuing professional development (CPD) is a "must" for school psychologists. In the U.S., the National Association of School Psychologists (NASP, 2000a; 2000b) indicates that it is a professional obligation to remain current regarding developments in research, training, and professional practices, In fact, NASP requires continuing professional development hours to be documented for renewal of the Nationally Certified School Psychologist (NCSP) credential (NASP, 1992; 2003). In England, the Division of Education and Child Psychology of the British Psychological Society (BPS, 1992) also indicates explicitly that CPD should be a career-long process that is obligatory for all school psychologists

Despite the consensus that CPD is indispensable to school psychology, relatively little research has been done in this area. There is a dearth of knowledge about the forms, frequency, popularity, and quality of the CPD activities in which school psychologists are engaged. In the past two decades, there were several questionnaire surveys conducted in the North America regarding professional supervision in school psychology (Chafouleas, Clonan, \& Vanauken, 2002; Fischetti \& Crespi, 1999; Ross \& Goh, 1993; Zins, Murphy \& Wess, 1989). Supervision is only one form of CPD activity. It is important to extend our knowledge to other forms beyond supervision. However, research regarding other forms of CPD is very limited. Recognizing the importance of CPD and the deficiency of knowledge in this area, there is a strong need to understand the current practices in order to project a path for future growth and development.

\section{School Psychology in Hong Kong}

The need to map out the current practices of CPD is particularly urgent for the school
Deleted: , one cannot assume that once students graduate from school psychology training programs, they are fully competent in the delivery of service. Currently

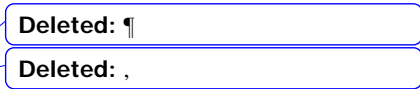

Deleted: that benefit children, family, and schools

Deleted: Under the proposed statutory registration of psychologists in England, Lunt (2002) advocates that mandatory CPD should be considered as "a means for revalidating practice and ensuring fitness to practice"(p.78)

Deleted: .

Deleted: However, research regarding other forms of CPD is very limited. Recognizing the importance of CPD and the deficiency of knowledge in this area, $t$ 
psychologists in Hong Kong. As a metropolis with a population of 6.8 million, Hong Kong is situated on the coast of the Guandong Province in the South China Sea. As a British colony for 155 years, it was reunited with the People’s Republic of China on July 1, 1997. The long period of British colonization has carved numerous Western features in Hong Kong's social, economic, legal, and political landscape. The profession of school psychology is one of Britain’s legacies in the educational system of Hong Kong. School psychology services have been introduced to Hong Kong since 1959. Hong Kong is the first place in Asia with a recognized vocation in school psychology and a post-graduate program for the professional preparation of school psychologists. Despite these developments, school psychology in Hong Kong is still very young when compared with its counterparts in the West. Up to now, Hong Kong does not have any regulatory system for school psychologists. It was only in recent years that the Hong Kong Psychological Society (HKPS) set up a working group for the preparation of statutory registration of psychologists. The HKPS is currently lobbying the Hong Kong Government to pass legislation that will govern the registration of psychologists. This strategic move is part of an endeavor to establish a comprehensive regulatory system for psychologists in Hong Kong. In any comprehensive regulatory system, mandatory CPD is an important component (Pryzwansky, 1993). With the implementation of statutory registration on the horizon, it is important to understand the current practices of the CPD activities of Hong Kong school psychologists.

There are likely to be some difficulties facing Hong Kong school psychologists during the establishment of regulatory system, these difficulties may be similar to those facing their counterparts in other parts of the world. The implementation of the NASP certification system in the U.S. once incited a discussion that was described by Crespi and Rigazio-DiGilio (1992) as an "intense three-way battle”. They noticed that on one side, some school psychologists Deleted: Although there is consensus in members of the profession may have very different views on how CPD activities should be counted towards license or certificate renewal.

Deleted: NCSP C favored restricted specific required training, whereas on a second front there were school psychologists who favored more open and flexible methods of acquiring CPD units. 
Additionally, there were also school psychologists who rejected any organizational requirements for continued certification whatsoever. It is anticipated that Hong Kong will likely experience similar conflicts in the process of establishing a regulatory system with mandatory CPD. The conflicts can be very intense if the engineers of the regulatory system do not understand and consider the current practices of their colleagues in CPD.

The endeavor to investigate CPD among Hong Kong school psychologists is not only meaningful to Hong Kong at this critical moment when a regulatory system is being introduced. It is also meaningful to the development of international school psychology. From a transnational perspective, Hatzichristou (2002) proposes a conceptual framework for understanding the evolution of school psychology. She delineates six common and interrelated components that define the profession of school psychology and influence its evolution. Legal issues related to certification-licensure are one of these components. The profession of school psychology in Hong Kong, like its counterparts in other parts of the world, has to address the issues of certification-licensure in its evolution. Being a pioneer in Asian school psychology Hong Kong's experience in this respect will provide a valuable resource not only to other Asian countries as they search for ways to start and develop school psychology, but also to Western school psychologists who are interested in the development of international school psychology.

\section{Research Questions}

The purpose of the present study is to investigate the current CPD activities of Hong Kong school psychologists. Specifically, this study examines whether school psychologists in Hong Kong have regular professional supervision, how often they have supervisory meetings, what background their supervisors have, and how they perceive and evaluate the supervision they receive. It is also important to know what other forms of CPD are popular among school psychologists in Hong Kong and how much time they spend on these activities. Last but not

Deleted: examines Deleted: Other than professional supervision, it

Deleted: they engage in frequently, what are the

Deleted: most

Deleted: forms,

Deleted: they 
the least, this study delineates what topics they consider top priority for their CPD、

Deleted: The answers to these questions will provide valuable information and insight regarding the future development of CPD among

school psychologists.

Method

Participants

Questionnaires were sent to all the practicing school psychologists in Hong Kong $(\mathrm{N}=$ 74). Thirty-two of them completed and returned the questionnaire. They comprised $43 \%$ of all the Hong Kong school psychologists in 2003. Among the respondents, 17 were in public schools, 13 were in government education centers while two were in private practice. On average they had 8.83 years of work experience in school psychology (SD =6.37). All of them had professional preparation in school psychology. One of them had doctoral degree and the remainder had a master's degree. There were more female $(\mathrm{N}=26)$ then male $(\mathrm{N}=6)$ respondents. The ratio between male and female was close to that of the population.

\section{Instrumentation}

The data presented in this paper were part of the data collected from the ISPA International School Psychology Survey when it was conducted in Hong Kong. This survey was developed by Shane Jimerson and the ISPA Research Committee (2002) in an attempt to collect information on school psychology in various countries of the world. The ISPS gathers information on training, roles, and responsibilities of school psychologists. It was piloted in Albania, Cyprus, Estonia, Greece, and North England (Jimerson, et al., in press). The ISPS used in Hong Kong also included some additional items and open-ended questions specifically to examine continuing professional development, The questionnaires were distributed and collected by mail.

\section{Results}

\section{Engagement in Professional Supervision}

Deleted: Participants in this study were 32 school psychologists in Hong Kong. They comprised $43 \%$ of all the practicing school psychologists in Hong Kong. In 2003, there were 74 practicing school psychologists in Hong Kong: 41 in public schools, 31 in government education centers, and 2 in private practice. The ratio between male and female school psychologists was 1 to 4.29 .

Questionnaires were mailed individually to all 74 school psychologists' in various regions of the territory. The

questionnaires were not sent to people who had qualifications in school

psychology but had retired or working in some capacity other than school psychologist (e.g., school principals and college professors). Reminder questionnaires were sent again to all 74 psychologists one month later.

Deleted: 32

Deleted: 1 to 4.33 . This ratio was Formatted: Indent: First line: $24 \mathrm{pt}$ Deleted: (See appendix for these additional items)

Deleted: ๆ

The English version of the ISPA International School Psychology Survey was used, given that school psychologists in Hong Kong are all trained overseas or Hong Kong universities using English as

a medium of instruction. The term

"educational psychologists" is used

throughout the questionnaire because

school psychologists in Hong Kong hold this particular title. The use of this title is a common practice in the United

Kingdom and British Commonwealth countries. The draft questionnaire was evaluated by an experienced school psychologist. Based on his feedback, the wording of some items was further refined for clarity within the cultural context. The questionnaire could be completed within 10 minutes.

\section{Deleted: ๆ}

Data Analysis

. The quantitative data were analyzed using SPSS. The qualitative responses for the open-ended question were categorized independently by both authors. The inter-rater reliability of the categorization was $87.4 \%$ (118 out of 135 responses). This paper presents only the results related to the practices and perceptions of CPD among the school psychologists in Hong Kong. ๆ 
Nineteen of the respondents (59.4\%) indicated that they currently received professional supervision. However, the percentage of school psychologists under regular supervision varied across different work settings. The percentages in public schools, government centers, and private practice were $64.7 \%, 61.5 \%$ and $0 \%$, respectively. It is noteworthy that none of the respondents who were in private practice reported that they received any supervision.

\section{Frequency of Supervision}

When asked how often they see their supervisors for supervision, more than $60 \%$ of these 19 respondents indicated that they saw their supervisors less than once a month Only $21 \%$ of these respondents indicated that they had supervisory meetings weekly.

Deleted:

\section{Characteristics of Supervisors}

Among the 19 respondents under supervision, all but one reported that their supervisors had at least master's degree in school psychology supervisor did not have master’s degree in school psychology but in social work.

On average, the number of school psychologists supervised by these supervisors was 5 with a range from 1 to $15(\underline{\mathrm{SD}}=3.84)$, The total number of staff supervised by the supervisors was 9.5 with a range from 1 to 25 and $\underline{\text { SD }}$ of 9.37 In general, supervisors from both public schools and government centers supervised not only school psychologists but also other staff. These data suggest that these supervisors were holding administrative positions in their organizations.

\section{Perception of Supervision}

To assess how the school psychologists in Hong Kong perceived the supervision they received, three statements about the satisfaction of supervision were included in the questionnaire. The respondents indicated their agreement to these statements on a 5-point

Deleted: . The supervisors in government centers tended to supervise more school psychologists $(\underline{\mathrm{M}}=8.20, \underline{\mathrm{SD}}$ $=4.66$ ) than their counterparts in public schools $(\underline{\mathrm{M}}=3.22, \underline{\mathrm{SD}}=1.79)$

Deleted: . The supervisors in government centers also tended to supervise more staff $\underline{(\underline{M}}=22.50, \underline{\mathrm{SD}}=$ 3.54) than their counterparts in public schools $(\underline{\mathrm{M}}=5.17, \underline{\mathrm{SD}}=5.49)$

Deleted: The total number of staff they supervised was larger than the total number of school psychologists they supervised. 
Likert scale with “ 1 ” for "strongly disagree” and “ 5 ” for "strongly agree.” The statements and the ratings are presented in Table 1 . Overall, the respondents did not think that they had obtained a great deal of benefit from the professional supervision $(\underline{\mathrm{M}}=2.54)$. There was no significant difference among the ratings of respondents from different work settings, $\underline{F}(2,23)$ $=1.24, \mathrm{p}>.05$. On average, these respondents did not agree that supervision for school psychologists in Hong Kong was adequate $(\underline{\mathrm{M}}=2.14, \underline{\mathrm{SD}}=.95)$. There was no significant difference regarding this matter among the respondents from different work settings, $\underline{F}(2,26)$ $=2.11, \underline{\mathrm{p}}>.05$. However, when asked if they wished to have more professional supervision than what they currently received, respondents from different work settings had very different responses, $\underline{F}(2,23)=11.84, \underline{p}>.001$. Post hoc Scheffe tests revealed that the respondents from public schools would like to receive more professional supervision $(\underline{\mathrm{M}}=4.07, \underline{\mathrm{SD}}=.88)$ than their counterparts in government centers $(\underline{\mathrm{M}}=2.56, \underline{\mathrm{SD}}=1.01)$ and private practice $(\underline{\mathrm{M}}$ $=1.50, \underline{\mathrm{SD}}=.71)$. Given that the respondents in government centers and private practice reported that supervision for school psychologists was inadequate in Hong Kong, it was counterintuitive that they did not wish to have more professional supervision.

\section{(Insert Table 1 about here)}

\section{Continuing Professional Development}

In the questionnaire, 9 types of CPD activities were included and respondents indicated how many hours they spent on each during the 2002/03 school year (see Table 2), The most popular types of CPD activities were the ones on which respondents spent the most hours. The respondents reported that they spent an average of 98.18 hours on self-study 44.79 hours on conferences or seminars in the previous school year. It is noteworthy that individual supervision only took up 8.45 hours from the respondents in the previous school year. This result was convergent with previous findings that the frequency of professional supervision

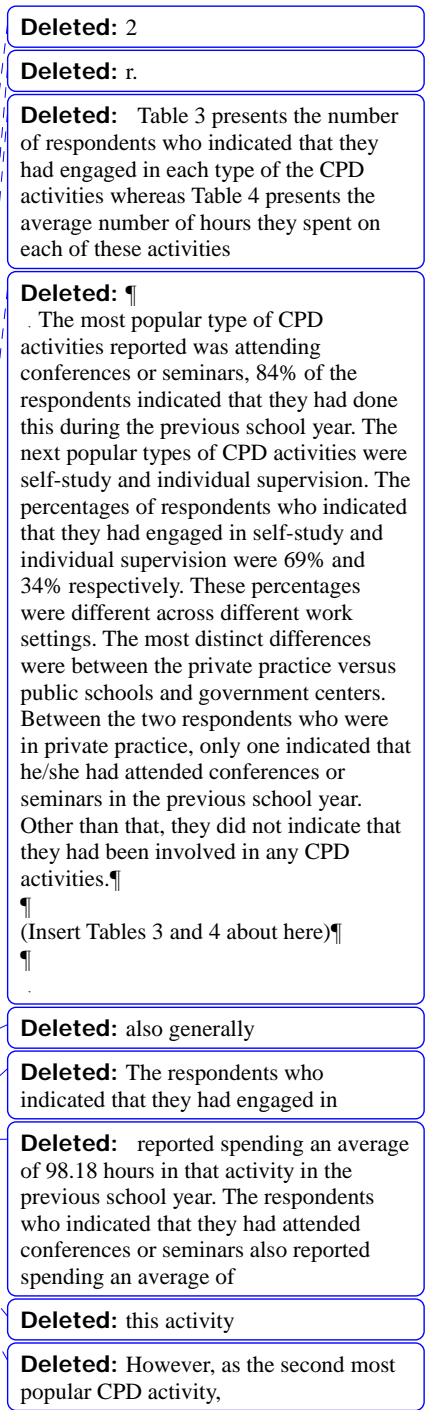


was not high among the school psychologists in Hong Kong. Differences were observed across different work settings. Between the two respondents who were in private practice, only one of them indicated that he/she spent 20 hours on conferences or seminars in the previous school year. Other than that, they did not indicate that they had been involved in any CPD activities.

\section{(Insert Table 2 about here)}

\section{Topics for Continuing Professional Development}

In the questionnaire, respondents were asked to indicate two topics that they considered top priority for their own CPD. Twenty-five respondents provided information for this open-ended question resulting in 45 topics. These topics are the areas in which they would like to further develop their skills and knowledge repertoire as school psychologists (e.g., therapeutic skills, intervention skills for learning difficulties, school consultation, etc.) We analyzed these topics with the service delivery model proposed by Lam (in press), In this model, the services of educational psychologists are conceptualized as having three dimensions: intervention, target, and directness. There are three levels in the intervention dimension: remedial, preventive, and developmental. The three levels in the target dimension are individuals, groups, and systems. There are two levels in the directness dimension: direct and indirect. Table 3 presents the summary of different levels and dimensions of this model.

(Insert Table 3 about here)

Topics generated by the respondents were then classified within this model. Each topic was classified into different levels for each of the three dimensions. For example, therapeutic skills were classified as remedial level in the intervention dimension, direct level in the

Deleted: Once again, $t$

Deleted: he major differences lay between private practice versus public schools and government centers.

Deleted: It is noteworthy that the standard deviations presented in Table 4 are quite large. The mean for the hours spent on self-study was 98.18 but the SD was 90.76 . The range was from 10 to 300 hours. The mean for the hours spent on attending conferences or seminars was 47.79 but the SD was 45.95 . The range was from 3 to 200 hours. The small sample size and high variation

undermines the reliability of the average results. Whereas the average number of hours spent on these activities seems to be large, there were many respondents who spent very little time on these activities. The average number was highly affected by one or two outliers.

Formatted: Centered 
directness dimension, and individual level in the target dimension. School improvement was classified as developmental level in the intervention dimension, indirect level in the directness dimension, and systems level in the target dimension. As there were 45 topics and each topic was classified three times, there were 135 results of classification. Each topic was classified independently by two reviewers. The overall agreement rate was $87.4 \%$ (118/135). There were 19 incidents that could not be classified because of inadequate information. For example, some respondents wrote down "school-consultation” without further explanation. It was agreed that school-consultation was at indirect level in the directness dimension but we could not determine if it was at remedial, preventive, or developmental levels in the intervention dimension when no further information was given. Thus, the analyses focused on the topics $(n=99)$ that had agreement and definite classification. In the intervention dimension, 48.5\% (16/33) of these topics were remedial in nature (e.g., psychotherapy) whereas 51.5\% (17/33) were preventive or developmental in nature (e.g., enhancing students' skills in learning and self-management). In the target dimension, 28.1\% (9/32) of these topics were targeted at individual (e.g., counseling skills), 31.3\% (10/32) were targeted at groups (e.g., teachers' stress), and 40.6\% (13/32) were targeted at the systems (e.g. education policy development). In the directness dimension, $29.4 \%$ (10/34) of these topics were related to direct services (e.g., treatment of children with emotion and behavior disorder), and 70.6\% (24/34) were related to indirect services (e.g., school consultation).

\section{Discussion}

The participants in the present study were 32 school psychologists in Hong Kong. Although the sample size was small, it constituted $43 \%$ of the total population of practicing school psychologists in Hong Kong. Thus, the data collected in the survey are likely representative of the practices and opinions among the school psychologists in Hong Kong.

Deleted: four

Deleted: Similarly, it was not possible to determine if it was at individual, group, or system levels in the target dimension.

Deleted: Other than analyzing the nature of the topics with Lam's model in service delivery (in press), the content of topics was also analyzed. Topics with similar content were grouped together and 11 themes emerged. The most popular theme $(n=10)$ was knowledge in teaching strategies and learning processes. Three respondents particularly pointed out that they would like to know more about neuropsychology and its

implications on teaching and learning. The next popular theme $(n=6)$ was psychotherapy or counseling skills. Systems work (e.g., school improvement, educational policy) was also another popular theme $(\mathrm{n}=5)$. School

consultation $(n=4)$ and students' social and emotional development $(n=4)$ were also themes mentioned frequently by the respondents.ๆ 


\section{Supervision in Hong Kong}

The findings indicated that $60 \%$ of the respondents received regular supervision, however, the majority met their supervisors less than once a month. The characteristics of their supervisors also suggested that the supervision tended to be administrative instead of professional in nature. There was also a supervisor who had no background in school psychology. In general, the respondents reported that supervision for school psychologists in Hong Kong was jnadequate. However, many of them (particularly those in government centers and the few in private practice) did not wish to have more professional supervision than what they got. The contradictory findings may be explained by the respondents' poor evaluation of the supervision they received. With reference to the findings presented in Table 1 , it is noteworthy that the respondents did not agree that they had obtained a great deal of benefit from the professional supervision in their jobs $(\mathrm{M}=2.54)$. When the respondents indicated that they had gained little benefit from the professional supervision in their jobs, they might mean very different things. Some may intend to communicate that the supervision was helpful but they had too little of it so that they had benefited little from it. Others may intend to suggest that the quantity of the supervision was okay but the quality was so bad that they had benefited little from it. Some may be attempting to communicate that both the quantity and quality of the supervision were so bad that they benefited little from it. The respondents from public schools might have espoused the first opinion whereas the respondents from government centers and private practice might have espoused second or third of these opinions. This may explain why the respondents from public schools wished to have more professional supervision $(\mathrm{M}=4.07)$ while the respondents from government centers $(M=2.56)$ and private practice $(M=1.50)$ did not. No matter what thoughts were involved when the respondents answered the questions, the results unequivocally indicate the serious deficiencies in professional supervision for school psychologists in Hong Kong.

Professional supervision is an important component of CPD. The NASP Standards for 
Provision of School Psychological Services (2000b) recommend individual face-to-face supervision for a minimum of one hour weekly by a supervising school psychologist for the first three years of practice with continued supervision after this initial employment period. The American Psychological Association (APA, 1981) has even more stringent requirements for professional supervision, specifying that non-doctoral school psychologist be supervised face-to-face for a minimum of one hour weekly by a professional psychologist who assumes overall responsibility for psychological services. This practice is to continue at all times throughout the careers of these non-doctoral psychologists. Only a single respondent of the present survey was a doctoral level psychologist. The results of the survey indicate that the practice of professional supervision in Hong Kong deviates substantially from recommended professional standards.

\section{$\underline{\text { International Supervision Satisfaction }}$}

The deficiencies of professional supervision for school psychologists are not a phenomenon unique to Hong Kong. The results of the present study were very similar to those of previous studies in the West (Chafouleas et. al., 2002; Fischetti \& Crespi, 1999; Ross \& Goh, 1993; Zins et al., 1989). In the late nineteen-eighties, Zins et al. (1989) found that less than $25 \%$ of the school psychologists surveyed were receiving individual or group supervision. In the early nineteen-nineties, Ross and Goh (1993) found that only about 30\% of the school psychologists in their study received regular formal supervision. The situation was not improved at the turn of millennium. Fishetti and Crespi (1999) found that 70\% of their respondents desired individual one-to-one clinical supervision but only $10 \%$ of them received it.

With regard to psychologists' dissatisfaction with the effectiveness of supervision, the Hong Kong school psychologists’ views are also consistent with those of their counterparts in the West. For example, only $37 \%$ of the supervisees in the Zins et al. study (1989) reported
Deleted:

Deleted: 9

Deleted: ๆ

International Supervision Satisfaction $\rrbracket$

Deleted: $95 \%$

Deleted: the respondents

Deleted: believed school psychologists should receive supervision, but only $37 \%$ of those who received supervision 
that supervision actually improved their service delivery skills. Similarly the respondents in Ross and Goh's survey (1993) did not highly value the supervision they received. Only 58\% of them reported that they would choose to receive supervision. The findings of a more recent study (Chafouleas et al., 2002) were not flattering either. The respondents in this recent study did not have high satisfaction with the supervision they received (2.68 out of a 5-point scale).

\section{Reconsidering and Redefining Supervision}

The lack of effective supervision for school psychologists seems to be a universal phenomenon. In view of the importance of professional supervision in CPD, school psychologists must come up with means to increase the opportunities to engage in quality supervision. One possible solution is to redefine supervision and make it more available, convenient, and helpful to school psychologists. Many school psychologists (e.g., Fischetti \& Crespi, 1999) define supervision as one-to-one clinical supervision between an experienced supervisor and a less experienced supervisee. Nevertheless, McIntosh and Phelps (2000) argue that this is not the only form of supervision. They suggest that group and peer supervision can be a viable alternative to receiving one-to-one clinical supervision. They redefine supervision as "an interpersonal interaction between two or more individuals for the purposes of sharing knowledge, assessing professional competencies, and providing objective feedback with terminal goals of developing new competencies, facilitating effective delivery of psychological services, and maintaining professional competencies” (p. 33). With this new definition, supervision does not require one-to-one monitoring. Neither does it require the supervisors to be more experienced or senior than the supervisees. Given the lack of quality supervisors, time constraints, and other unfavorable conditions in the work of school psychologists (e.g., heavy workload), group and peer supervision may better fulfill the functions of supervision than one-to-one clinical supervision. Exchanges among groups of professionals can serve as a vehicle for sharing professional knowledge and providing
Deleted: When asked to evaluate the effectiveness of supervision on a 4-point Likert scale (1= Not Useful At All to $4=$ Very Useful), a mean of $2.8(\mathrm{SD}=1.0)$ was obtained from the school psychologists who were under supervision. In the same survey, o

Deleted: the respondents 
feedback. In a similar vein, Kruger, et al. (2001) advocate that the internet-based learning community among peers is a promising approach to provide relevant professional information and on-line social support among school psychologists regionally and globally.

Other than the adoption of peer supervision and the cultivation of an internet-based learning community, an introduction of a regulatory system with mandatory CPD is another way to increase the engagement in professional supervision, However, Hong Kong does not have any regulatory system for psychologists. The registration of psychologists is not mandatory in Hong Kong. Many psychologists can practice without registration. ,The regulation of the professional practice of those who have not registered is left to their employers. One alarming result of the present study was the large variation in the engagement of CPD activities among school psychologists from different work settings. The school psychologists in private practice engaged least in CPD activities. None of them reported that they had any professional supervision. Because school psychologists in private practice are self-employed, their practices are left un-monitored. Until statutory registration is implemented, little can be done to improve this situation.

\section{Continuing Professional Development Practices}

If a regulatory system with mandatory CPD is introduced to improve the engagement of school psychologists in CPD, it is important to know their current practices so that the rules and regulations can cater for their needs. The results of the present study indicated that the most popular types of CPD activities were self study and attending conferences or seminars, The respondents indicated that they spent most time in self-study. This is consistent with previous findings by Oakland \& Cunningham (1992). In their international school psychology survey, many school psychologists replied on reading professional literature for their CPD. As self-study is difficult to quantify, document, and verify, it was not included as one of the categories of CPD activities in the proposal for CPD drafted by the Division of
Deleted: group and

Deleted: . According to the proposal for
CPD drafted by the Division of
Educational Psychology (DEP) of the
Hong Kong Psychological Society (2001),
receiving professional supervision is one
of the categories of CPD activities. With
a regulatory system in place, school
psychologists who want to renew their
registration or certification are required to
engage in various CPD activities
including professional supervision
Deleted: It is only on a voluntary basis.
Deleted: According to the list provided
by the Registration Board of the Hong
Kong Psychological Society, there were
only 33 registered-school psychologists
in Hong Kong by 2002 .


Educational Psychology (DEP) of the Hong Kong Psychological Society (2001). However, if self-study is a popular CPD activity, there is a need for regulatory organizations to develop systems that school psychologists can document their engagement in self-study so that CPD units can be earned.

Recently the Hong Kong Psychological Society (2003) released a consultation paper that included self-study as one of the categories of CPD activities, With reference to the results of the present study, this new consultation paper is an improvement The inclusion of such a popular category of CPD activities will win the support from more school psychologists for the establishment of a regulatory system. It will also ease the resistance of the school psychologists who do not like organizational requirements for continued certification.

\section{Priorities for Continuing Professional Development}

Despite the lack of professional supervision and regulatory system, there are strengths in the school psychology in Hong Kong. When we asked the respondents to write down two topics that they considered top priority for their CPD, respondents reported a healthy balance of topics related to direct and indirect services The topics also covered a wide range of services that included remedial, preventive and developmental interventions. The targets of services did not only include individuals but also groups and systems. The findings indicate that the school psychology services in Hong Kong are moving away from the traditional model of direct services to a more comprehensive school psychology services model. The respondents were aware of the changes and specified consciously that they would like to see themselves have CPD in wide range of services that go beyond the traditional service delivery model that focuses on remedial work with individual students.

\section{Conclusion}

Legal issues related to certification-licensure are one of the common components in the

Deleted: . The calculation of a CPD unit was proposed as follows: 1 CPD unit for a 300-word written report for journal articles; 3 CPD units for a 600-word written report for a book, and 1 CPD unit for a 300-word report for 1-hour video

Deleted: to the proposal of the Division of Educational Psychology (2001)
Deleted: This is consistent with an earlier survey study by Lam and Mak (1998) showing that the ratio between direct and indirect intervention was 1 to 5.8 among school-based psychologists in regular schools.
Deleted: Examination of the content of these topics revealed that many respondents liked to learn more about teaching strategies and learning processes. Some particularly specified that they would like to know more about neuropsychology and its implications for teaching and learning. These results reflect a general demand among school psychologists in Hong Kong for CPD in systems intervention related to teaching and learning. The respondents were sensitive to the new development in this area and explicitly expected themselves to keep updated. This information is useful to the organizers of CPD activities for school psychologists. When they plan the relevant activities, they should keep this in mind and try their best to cater to the demands of the profession. I

Deleted: As Hatzichristou (2002) proposes in her transnational model, 1 
evolution of school psychology across nations (Hatzichristou, 2002). Mandatory CPD is an important part of a comprehensive certification-licensure system. On the verge of establishing such a system in Hong Kong, this study examined how Hong Kong school psychologists practiced and perceived CPD. The present survey revealed the deficiency of professional supervision for school psychologists in Hong Kong. The results re-affirm the need for a regulatory system with mandatory CPD. They also inspire us to rethink the definition of professional supervision, to reconsider the organization requirements for CPD, and to re-emphasize the need to organize CPD activities that can cater for the demands of the profession. Given the lack of quality supervisors and other unfavorable work conditions, group and peer supervision may be good vehicles for sharing professional knowledge and providing objective feedback. Given the popularity of self-study in CPD, regulatory organizations should develop systems to document and acknowledge the engagement in this activity. Given the general demand from the profession for a more comprehensive service delivery model, organizers of CPD activities should be aware of this demand. From a transnational perspective, these lessons learned by Hong Kong school psychologists may well be shared by their counterparts in other countries when they are also at the stage of introducing regulatory systems with mandatory CPD. In the future, it would be interesting to compare the perceptions, planning and provisions of CPD among school psychologists in different countries. We are looking forward to the future data from the ISPA International School Psychology Survey. The results of this survey will yield invaluable information regarding school psychology in various countries of the world. 


\section{References}

American Psychological Association. (1981). Specialty guidelines for the provision of services by school psychologists. American Psychologist, 36, 670-681.

British Psychological Society (DECP) (1992). Continuing professional development: A personal record. Leicester: BPS, DECP.

Chafouleas, S., Clonan, S. M., \& Vanauken, T. L. (2002). A national survey of current supervision and evaluation practices of school psychologists, Psychology in the Schools, 39, 317-325.

Crespi, T. D., \& Rigazio-Digilio, S. A. (1992). Professional development and continuing education: Implications for the school psychologist. School Psychology International, 13, 347-355.

Division of Educational Psychology, the Hong Kong Psychological Society (2001). Principles and guidelines on continuing education for educational psychologists. Hong Kong: Author.

Fischetti, B.A., \& Crespi, T.D. (1999). Clinical supervision for school psychologists: national practices, trends and future implications. School Psychology International, 20, 3,278-288.

Hatzichristou, C. (2002). A conceptual framework of the evolution of school psychology: Transnational considerations of common phases and future perspectives. School Psychology International, 23, 266-282.

Jimerson, S. R., Graydon, K., Farrell, P., Kikas, E., Hatzichristou, C., Boce, E., Bashi, G., \& The ISPA Research Committee (in press). The International School Psychology Survey: Development and Data. School Psychology International.

Jimerson, S. R., \& ISPA Research Committee (2002). The international school psychology survey. Available from author at the University of California, Santa Barbara 
<Jimerson@education.ucsb.edu>.

Kruger, L. J., Macklem, G., Burgess, D.M., Maital, S.L., Shirberg, D., \& Kalinsky, R. (2001).

Sense of community among school psychologists on an internet site. Professional Psychology: Research and Practice. 32(6), 642-649.

Lam, S. F. (in press). The growth and development of school psychology in Hong Kong. In C.

L. Frisby \& C. Reynolds (Eds.), Handbook of Multicultural School Psychology.

McIntosch, D.E., \& Phelps, L. (2000). Supervision in school psychology: where will the future take us? Psychology in the Schools, 37, 33-38.

National Association of School Psychologists (1992). NCSP renewal guidelines: Nationally certified school psychologist continuing professional development program. Bethesda, MD: Author.

National Association of School Psychologists. (2000a). Professional conduct manual. Bethesda, MD: Author.

National Association of School Psychologists. (2000b). Standards for the Provision of School Psychological Services. Bethesda, MD: Author.

National Association of School Psychologists (2003). NCSP renewal guidelines: Nationally certified school psychologist continuing professional development program. Bethesda, MD: Author.

Oakland, T.D., \& Cunningham, J.L. (1992). A survey of school psychology in developed and developing countries. School Psychology International, 13, 99-129.

Pryzwansky, W. B. (1993). The regulation of school psychology: A historical perspective on certification, licensure, and accreditation. Journal of School Psychology, 31, 219-235.

Ross, R.P., \& Goh, D.S. (1993). Participating in supervision in school psychology: A national survey of practices and training. School Psychology Review, 22,1, 63-81.

The Hong Kong Psychological Society. (2003). Consultation of the principles and guidelines

Deleted: Lam, S. F., \& Mak, Y. S. (1998). The changing roles of educational psychologists in Hong Kong. School Psychology International, 19(4), 317-340. बा

Lunt, I. (2002). Competence, fitness to practice and continuing professional development: the ethical basis of educational psychologists' practice. Educational and Child Psychology, 19(1), 70-80.

Deleted: Available on-line; www.nasponline.org

Formatted: Default Paragraph Font 
on continuing professional education in the Institute of Psychologists. Hong Kong:

Author.

Zins, J. E., Murphy, J. J., \& Wess, B. P. (1989). Supervision in school psychology: current practices and congruence with professional standards. School Psychology Review, $18,56-63$.

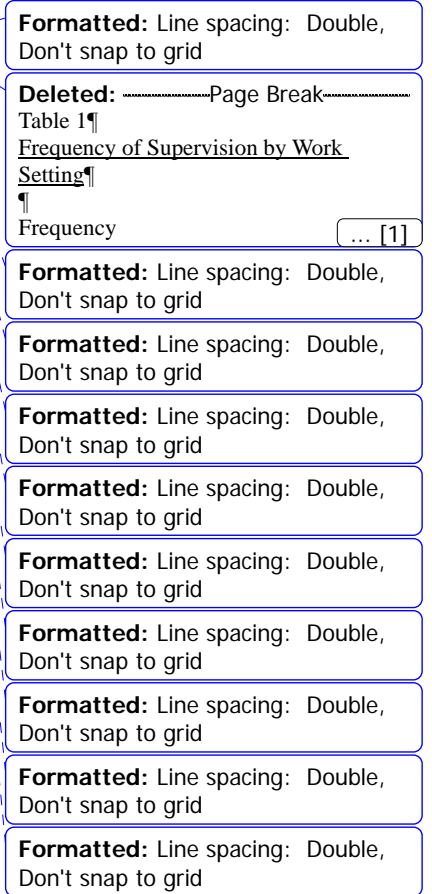


Table 1

Perception and Evaluation of Supervision by Work Setting

\begin{tabular}{|c|c|c|c|c|}
\hline & $\begin{array}{c}\text { Public } \\
\text { Schools } \\
(n=17)\end{array}$ & $\begin{array}{l}\text { Government } \\
\text { Centers } \\
(n=13)\end{array}$ & $\begin{array}{l}\text { Private } \\
\text { Practice } \\
(n=2)\end{array}$ & $\begin{array}{l}\text { Total } \\
(\mathrm{n}=32)\end{array}$ \\
\hline $\begin{array}{l}\text { I have benefited a lot from the } \\
\text { professional supervision in my } \\
\text { job. }\end{array}$ & $\begin{array}{l}2.86 \\
(1.29)\end{array}$ & $\begin{array}{l}2.20 \\
(.92)\end{array}$ & $\begin{array}{l}2.00 \\
(0)\end{array}$ & $\begin{array}{l}2.54 \\
(1.14)\end{array}$ \\
\hline $\begin{array}{l}\text { In general, supervision for } \\
\text { school psychologists is adequate } \\
\text { in Hong Kong. }\end{array}$ & $\begin{array}{l}1.80 \\
(.94)\end{array}$ & $\begin{array}{l}2.50 \\
(.91)\end{array}$ & $\begin{array}{l}2.00 \\
(.71)\end{array}$ & $\begin{array}{l}2.14 \\
(.95)\end{array}$ \\
\hline $\begin{array}{l}\text { I wish I had more professional } \\
\text { supervision than what I get now. }\end{array}$ & $\begin{array}{l}4.07^{\mathrm{a}} \\
(.88)\end{array}$ & $\begin{array}{l}2.56^{\mathrm{b}} \\
(1.01)\end{array}$ & $\begin{array}{l}1.50^{\mathrm{b}} \\
(.71)\end{array}$ & $\begin{array}{l}3.35 \\
(1.26)\end{array}$ \\
\hline
\end{tabular}

Note. The numbers in parentheses are standard deviations. The means with different superscripts are significantly different from each other. 
CONTINUING PROFESSIONAL DEVELOPMENT 21

Table 2

Number of Hours Spent on Various CPD Activities in the Previous School Year

\begin{tabular}{|c|c|}
\hline \multicolumn{2}{|c|}{ Types of CPD Activities } \\
\hline & $\begin{array}{l}\text { Attending conferences / } \\
\text { workshops / seminars / } \\
\text { lectures / forums }\end{array}$ \\
\hline & $\begin{array}{l}\text { _Receiving individual } \\
\text { supervision }\end{array}$ \\
\hline & $\begin{array}{l}\text { Receiving group/peer } \\
\text { supervision }\end{array}$ \\
\hline & $\begin{array}{l}\text { Receiving professional/ } \\
\text { psychological service for } \\
\text { personal growth/training } \\
\text { purposes }\end{array}$ \\
\hline & $\begin{array}{l}\text { Self-study (e.g., reading } \\
\text { journal articles, books or } \\
\text { watching teaching videos) }\end{array}$ \\
\hline$\underline{6 .}$ & $\begin{array}{l}\text { Teaching a program or } \\
\text { course, or offering a seminar } \\
\text { or workshop to fellow school } \\
\text { psychologists }\end{array}$ \\
\hline & $\begin{array}{l}\text { Providing supervision to } \\
\text { school psychology trainees in } \\
\text { an internship or practicum }\end{array}$ \\
\hline & $\begin{array}{l}\text { Publishing articles in } \\
\text { newspapers or magazines }\end{array}$ \\
\hline$\underline{9 .}$ & $\begin{array}{l}\text { Publishing articles in } \\
\text { trade/academic journals, or } \\
\text { books }\end{array}$ \\
\hline
\end{tabular}

(2.83)

(10.61)

6.75

10

0

(3.95)
Deleted: Table 39

Number of Respondents Who Engaged in CPD Activities in the Previous School Year"

ฯ

Types of CPD Activities [2]

Formatted: Bullets and Numbering

$\begin{array}{llll}(27.51) & (63.32) & (0) & (45.95)\end{array}$

$\begin{array}{rrrr}6.38 & 14.00 & 0 & 8.45 \\ (2.77) & (14.42) & (0) & (7.72) \\ 17.5 & 16 & 0 & 17.33 \\ 11.25) & (0) & (0) & (10.54) \\ 19.57 & 50 & 0 & 23.38 \\ 19.65) & (0) & (0) & (21.13)\end{array}$

Formatted: Bullets and Numbering

Formatted: Bullets and Numbering

Formatted: Bullets and Numbering

$\begin{array}{lrrr}77.14 & 135.00 & 0 & 98.18\end{array}$

$\begin{array}{llll}(85.29) & (93.66) \quad(0) \quad \text { (90.76) }\end{array}$

$\begin{array}{rrrr}4.50 & 10.50 & 0 & 6.90 \\ (2.60) & (13.44) & (0) & (7.70)\end{array}$

$\begin{array}{llll}8.00 & 42.50 & 0 & 25.25\end{array}$

(0) (20.90)

7.40

(0) (0) (3.715)

24.57

(0) (13.00)
0

(0)

24.57
$(13.00)$
Formatted: Bullets and Numbering

Formatted: Bullets and Numbering

Formatted: Bullets and Numbering

Note. The numbers in parentheses are standard deviations. 
Table 3

Summary of Service Delivery Model Proposed by Lam (in press)

\begin{tabular}{|c|c|c|c|}
\hline Dimensions & Levels & Focus & Examples \\
\hline \multirow[t]{3}{*}{ Intervention } & Remedial & $\begin{array}{l}\text { Treatment of problems } \\
\text { or dysfunctions that have } \\
\text { occurred }\end{array}$ & $\begin{array}{l}\text { Anger control training } \\
\text { for a student with } \\
\text { aggressive behaviors }\end{array}$ \\
\hline & Preventive & $\begin{array}{l}\text { Prevention of } \\
\text { dysfunction or problems } \\
\text { that have not occurred or } \\
\text { about to occur }\end{array}$ & $\begin{array}{l}\text { Assertiveness training } \\
\text { for a group of student } \\
\text { at risk of being bullied }\end{array}$ \\
\hline & Developmental & $\begin{array}{l}\text { Enhancement and } \\
\text { enrichment of positive } \\
\text { qualities }\end{array}$ & $\begin{array}{l}\text { Leadership training for } \\
\text { peer tutors in } \\
\text { cooperative learning }\end{array}$ \\
\hline \multirow[t]{3}{*}{ Target } & Individual & Individual students & $\begin{array}{l}\text { Counseling service for } \\
\text { a student who has been } \\
\text { referred for learning } \\
\text { difficulties }\end{array}$ \\
\hline & Group & $\begin{array}{l}\text { Groups of students, } \\
\text { teachers, educational } \\
\text { administrators, or } \\
\text { parents }\end{array}$ & $\begin{array}{l}\text { Staff development } \\
\text { workshops on catering } \\
\text { for student diversity }\end{array}$ \\
\hline & Systems & $\begin{array}{l}\text { The systems in which the } \\
\text { individual child resides, } \\
\text { such as classrooms, } \\
\text { schools, and families }\end{array}$ & $\begin{array}{l}\text { Consultation with } \\
\text { teachers on curriculum } \\
\text { development }\end{array}$ \\
\hline \multirow[t]{2}{*}{ Directness } & Direct & $\begin{array}{l}\text { Activities performed } \\
\text { directly on the targets }\end{array}$ & $\begin{array}{l}\text { Assessment of a } \\
\text { student with special } \\
\text { needs }\end{array}$ \\
\hline & Indirect & $\begin{array}{l}\text { Activities implemented } \\
\text { around the targets in } \\
\text { their environment }\end{array}$ & $\begin{array}{l}\text { Consultation with } \\
\text { parents and teachers } \\
\text { regarding the special } \\
\text { needs of a student }\end{array}$ \\
\hline
\end{tabular}

Deleted: 5

Formatted: Snap to grid

Deleted: १$$
\text { ( }
$$$$
\text { ฯ }
$$$$
\text { ๆ }
$$$$
\text { ฯ }
$$$$
<\text { sp }><\text { sp }>\text { q }
$$

ๆ

$<$ sp $><$ sp $><$ sp $><$ sp $><$ sp $><$ sp $><$ sp $><$ sp $>$

$<$ sp $><$ sp $><$ sp $><$ sp $><$ sp $><$ sp $><$ sp $><$ sp $>$

$<$ sp $>$ ฯ

व

$<$ sp $>$ ฯ

ๆ

๑

Formatted: Snap to grid

Formatted: Snap to grid

Formatted: Snap to grid

Formatted: Snap to grid

Formatted: Snap to grid

Formatted: Snap to grid

Formatted: Snap to grid

Formatted: Snap to grid

Formatted: Snap to grid

Formatted: Snap to grid

Formatted: Snap to grid

Formatted: Snap to grid

Formatted: Snap to grid

Formatted: Snap to grid

Formatted: Snap to grid

Formatted: Snap to grid

Formatted: Snap to grid

Formatted: Snap to grid

Formatted: Snap to grid

Formatted: Snap to grid

Formatted: Snap to grid

Formatted: Snap to grid

Formatted: Snap to grid

Formatted: Snap to grid

Formatted: Snap to grid

Formatted: Snap to grid 
Table 1

Frequency of Supervision by Work Setting

\begin{tabular}{|c|c|c|c|}
\hline \multirow[t]{2}{*}{ Frequency } & Public Schools & $\begin{array}{l}\text { Government } \\
\text { Centers }\end{array}$ & Total \\
\hline & $(\mathrm{n}=11)$ & $(n=8)$ & $(n=19)$ \\
\hline
\end{tabular}

\begin{tabular}{llll}
\hline Weekly & 2 & 2 & 4 \\
& $(18.2 \%)$ & $(25.0 \%)$ & $(21.1 \%)$ \\
Monthly & 3 & 0 & 3 \\
& $(27.3 \%)$ & $(0 \%)$ & $(15.8 \%)$
\end{tabular}

Less than once a month

6

6

12

(54.6\%)

(75.0\%)

(63.2\%)

Page 21: [2] Deleted

Lam S. F.

4/ 1/ 2004 4:15:00 PM

Table 3

Number of Respondents Who Engaged in CPD Activities in the Previous School Year

\begin{tabular}{|c|c|c|c|c|}
\hline Types of CPD Activities & $\begin{array}{l}\text { Public } \\
\text { Schools } \\
(n=17)\end{array}$ & $\begin{array}{c}\text { Government } \\
\text { Centers } \\
(n=13)\end{array}$ & $\begin{array}{c}\text { Private } \\
\text { Practice } \\
(n=2)\end{array}$ & $\begin{array}{l}\text { Total } \\
(n=32)\end{array}$ \\
\hline Attending conferences / & 16 & 10 & 1 & 27 \\
\hline $\begin{array}{l}\text { workshops / seminars / lectures / } \\
\text { forums }\end{array}$ & $(94.1 \%)$ & $(76.9 \%)$ & $(50 \%)$ & $(84 \%)$ \\
\hline Receiving individual supervision & 8 & 3 & 0 & 11 \\
\hline
\end{tabular}


Receiving group/peer supervision

Receiving professional/

psychological service for personal growth/training purposes

Self-study (e.g., reading journal articles, books or watching teaching videos)

Teaching a program or course, or offering a seminar or workshop to fellow school psychologists

Providing supervision to school psychology trainees in an internship or practicum

Publishing articles in newspapers or magazines

Publishing articles in trade/academic journals, or books

(47.1\%)

8

(23.1\%)

(0\%)

(34\%)

(47.1\%)

7

$(47.2 \%)$

14

(82.4\%)

3

(17.6\%)

$(7.7 \%)$

$(0 \%)$

(28\%))

7

1

$(7.7 \%)$

(0\%)

(25\%)

(1)

$(61.5 \%)$
0
22
8

$(0 \%)$

(69\%)

$\begin{array}{llll}2 & 0 & 5\end{array}$

$(15.4 \%) \quad(0 \%) \quad(15.6 \%)$

$\begin{array}{llll}2 & 2 & 0 & 4\end{array}$

(11.8) (15.4\%) (0\%) (12.5\%))

$4 \quad 1 \quad 005$

$\begin{array}{llll}(23.5 \%) & (7.7 \%) & (0 \%) & (15.6 \%)\end{array}$

$\begin{array}{rrrr}7 & 0 & 0 & 7\end{array}$

$(47.2 \%) \quad(0 \%) \quad(0 \%) \quad(21.9 \%)$

Note. The numbers in parentheses are percentages.

Table 4

Page Break

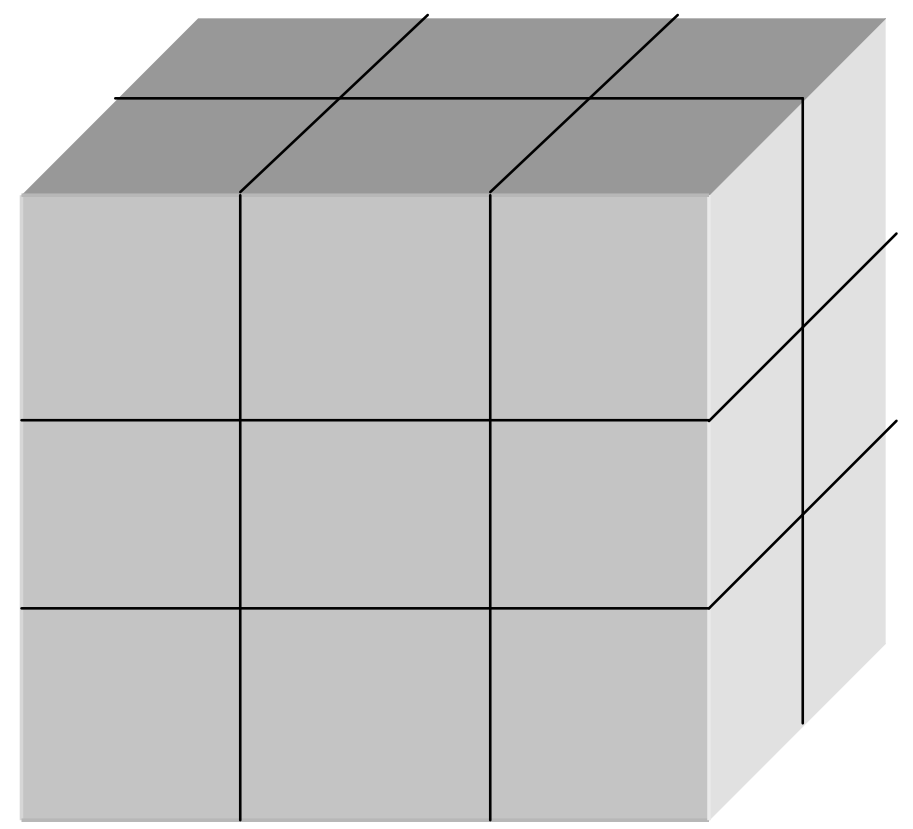

Developmental

Indirect 
Figure 1. Conceptualization of school psychology services.

\section{Appendix}

Page Break

\section{Questionnaire Items Related to Continuing Professional Development}

Do you receive supervision as an educational psychologist?

yes

no

If yes, please indicate all of the following characteristics that describe your immediate supervisor:

degree in school psychology

degree in other area; please specify: doctoral degree masters degree bachelors degree number of school psychologists your supervisor supervises total number of staff supervised by your supervisor

2. How often do you see your supervisor for supervision? weekly bi-weekly monthly less than once a month

3. How much do you agree to the following statements?

\section{Strongly disagree}

I have benefited a lot from the professional supervision in my job.

In general, supervision for school psychologists is $\quad \begin{array}{lllllll}1 & 2 & 3 & 4 & 5\end{array}$ adequate in Hong Kong.

I wish I had more professional supervision than what I $\begin{array}{llllll}1 & 2 & 3 & 4 & 5\end{array}$ get now.

In this school year (2002/03), how many hours did you spend on the following activities of continuing professional education? 
Attending a conference / workshop / seminar / lecture / forum __ hrs Receiving supervision (e.g., individual, group, peer) _ hrs Receiving professional/psychological service for personal $\quad-$ hrs growth/training purposes Self-study (e.g., reading journal articles, books or watching teaching ___ hrs videos)

Teaching a program or course, or offering a seminar or workshop to professionals

Providing supervision to trainees or students in an internship or practicum

Publishing articles in newspapers or magazines

Publishing articles in trade/academic journals, or books rs hrs hrs hrs hrs

Please state two topics that you consider top priority for your own continuing professional development.

Note. Questions 3 to 5 are items added to the ISPA International School Psychology Survey when it was conducted in Hong Kong. 